\title{
RESISTENCIAS LOCALES FRENTE A LOS DISEÑOS GLOBALES MEDIANTE LAS MANIFESTACIONES ARTÍSTICAS RELIGIOSAS SINCRÉTICAS. CASO: LAS NEGRERAS DE MOSQUEY, BOCONÓ-TRUJILLO, VENEZUELA
}

\author{
LOCAL RESISTANCE TO GLOBAL DESIGNS THROUGH SYNCRETIC \\ RELIGIOUS ARTISTIC MANIFESTATIONS. CASE: THE NEGRERAS \\ OF MOSQUEY, BOCONÓ-TRUJILLO, VENEZUELA
}

\author{
Felipe A. Bastidas T.*
}

\begin{abstract}
Las comunidades campesinas invisibilizadas y subalternizadas han sabido ocultar -de manera consciente primero, e inconsciente después- sus epistemes y subjetividades en sus manifestaciones artísticas sincréticas religiosas. La innovación de estas tradiciones también puede ser considerada un pensamiento fronterizo por su historia de diálogo y sobrevivencia con las instituciones modernas. Algunas de estas comunidades al perder el sentido de la raíz socio-productiva de sus manifestaciones también sufren la desarticulación de su identidad. Paradójicamente, la comunidad andina de Mosquey, al verse presionada a pasar de rural a urbana en menos de treinta años, no solo ha innovado una festividad con préstamos culturales de otras localidades, sino que las puede estar usando como sujeción de una identidad local y una forma de resistencia a los diseños globales del sistema-mundo moderno; de este modo, abre un horizonte de estudio para los investigadores sociales críticos.

Palabras claves: Resistencia cultural, diseños globales, manifestaciones artísticas sincréticas religiosas, Boconó, Negreras de Mosquey, identidad local.
\end{abstract}

The peasant communities are invisible and subalternized, nevertheless, they have known how to consciously conceal first, and then unconsciously, their epistemes and subjectivities in their syncretic religious artistic manifestations. The innovation of these traditions can also be considered a border thinking because of its history of dialogue and survival with modern institutions. Some of these communities, by losing the sense of the socio-productive root of their manifestations, also suffer the disarticulation of their identity. Paradoxically, the andean community of Mosquey, when being pressured to move from rural to urban in less than thirty years, has not only innovated a festivity with cultural loans from other localities, but may be using them as a subjection of a local identity and a form of resistance to the global designs of the modern world-system; in this way, it opens a study horizon for critical social researchers.

Key words: Cultural resistance, global designs, religious syncretic artistic manifestations, Boconó, Negreras de Mosquey, local identity.

\section{Relectura de las manifestaciones artísticas sincréticas religiosas bajo la perspectiva de los estudios decoloniales}

Las ciencias sociales, no han podido hasta ahora, realizar estudios sistemáticos en torno a las manifestaciones artísticas sincréticas religiosas, en parte, porque los enfoques se han construido como los estudios del folclor, de la cultura popular o tradicional, ambas analizadas en contraposición a la racionalidad moderna. Para García Canclini (1990) estos estudios fueron iniciados desde el siglo XIX, y prosiguieron en la primera mitad del siglo XX, con una orientación más ideológica que científica debido a la debilidad de una fundamentación y coherencia epistemológica que generó una serie de estudios descriptivos con énfasis en los productos, más que en los procesos y la relaciones; desde diversas disciplinas, no se ha dado con los criterios epistémicos e instrumentales para aproximarse de mejor forma a las subjetividades de quienes practican estas festividades.

Las manifestaciones artísticas sincréticas religiosas han sido perforadas por la diferencia colonial $^{1}$, verbigracia, han sido subalternizadas, incluyendo las categorías establecidas por De

\footnotetext{
* Universidad de Carabobo. Grupo de Investigación Alteridad Latinoamericana y Caribeña. Carabobo, Venezuela. Correo electrónico: fabastidas@gmail.com, bfelipe@uc.edu.ve,
} 
Sousa (2010), es decir, han sido catalogadas por la matriz epistémica del poder moderno como: locales/particulares, improductivas/estériles, retrasadas, ignorantes, inferiores; todo esto con respecto al conocimiento moderno. Esta idea tiene un precedente con García Canclini (1990) quien establece que las dicotomías sobre este tipo de manifestaciones provienen de la lógica moderno/tradicional, culto/popular, hegemónico/ subalterno.

Se escogió el término manifestaciones artísticas religiosas sincréticas ${ }^{3}$, para hacer alusión a las festividades y celebraciones donde se combinan, de forma aparente, elementos religiosos y artísticos de índole ancestral-indígena con los cristianos traídos por los hispanoárabes ${ }^{2}$ (y posteriormente con elementos afrosubsaharianos), que no han dejado de innovarse con distintos préstamos culturales.

Se parte de la premisa de que los damné $e^{4}$ ancestrales andino, afrosubsahariano, e incluso ibérico-islámico ${ }^{5}$, depositaron -de forma encubierta- detrás del sincretismo religioso sus subjetividades, específicamente en el campesino como heredero directo de él; el giro decolonial consiste en asumir que hay conocimiento allí innovado, además, al pasar de generación en generación, las manifestaciones artísticas religiosas sincréticas contienen una forma pacífica y eficaz de interculturalidad entre los pueblos ancestrales $\mathrm{y}$ tradicionales, mediante sus sincretismos innovados por el campesino andino como una forma de resistencia e interlocución frente a la modernidad, y luego fue asumido como un modo de vida (Cf. Suárez de Paredes y Castillo, 2002). Este tipo de manifestaciones permitieron esconder detrás del sincretismo saberes y subjetividades alternos a la modernidad, por ende, pueden dar pistas para la decolonialidad: para salir del entrampamiento del sistema mundo moderno ${ }^{6}$ cuya lógica ha puesto en peligro al planeta.

Todo esto lleva a hacer una relectura de las manifestaciones artísticas sincréticas religiosas como pensamiento fronterizo que pueden conducir al giro decolonial., es decir, asumirlas desde las fronteras entre la modernidad y las sociedades y comunidades locales subalternizadas, que pueden dar una crítica doble: desde la modernidad y fuera de ella. El pensamiento fronterizo es criticar y reflexionar sobre la modernidad para salir de ella y su crisis civilizatoria (Walsh 2007; Lepe 2008).

\section{Contextualización espaciotemporal y sociocultural de la manifestación artística sincrética religiosa del estudio}

Gracias a su unidad lingüística las etnias cuicas $^{7}$ ubicadas en la región hoy denominada Trujillo, participaban de un intercambio comercial con otras etnias del occidente del territorio hoy conocido como Venezuela (Dubuc de Isea 2013; Warner, 1987; Rengifo 2006). Las etnias cuicas tuvieron presencia desde el siglo VII a.C. con un desarrollado sistema agrícola por terrazas (andenes) (Albarrán et al., 2014).

Esta capacidad y organización del modo de producción basado en la agricultura de las etnias que componían la unidad lingüística cuica determinaron la distribución de sus asentamientos en el espacio y fue la base para el poblamiento e implantación de la sociedad colonial y finalmente la sociedad nacional hasta la primera mitad del siglo XIX (Moreno, 1994). En las manifestaciones religiosas vinculaban los hechos cotidianos con elementos naturales representados como dioses, siendo el sol (Ches) y la luna (Chía) los principales; con un centro de peregrinación para adorar la diosa Icaque en la región de los escuqueyes; la estructura social de los cuicas era simple, constituida por un consejo de ancianos encargado de la legislación y el acatamiento de las normas de convivencia, el Tabiskey o Chacoy quien era el líder político y militar. Existía la figura del Toy, una especie de chamán (Albarrán et al., 2014).

La organización social se constituyó por sistemas de asentamientos interdependientes con un alto grado de autonomía, sistema más o menos emulado en la sociedad colonial y luego en la sociedad nacional (Rengifo 2006).

Dentro de los sistemas de asentamientos de los cuicas, llama la atención el del hoy denominado valle de Boconó, quienes formaban un sistema de asentamientos autónomos e interdependientes que compartían rituales religiosos además de la lengua. El proceso de conquista fue efectivo para la posterior implantación de la sociedad colonial, la cultura de las etnias cuicas distribuidas en aldeas fue destruida incorporando y absorbiendo algunos de sus elementos a la posterior sociedad nacional, tal como lo teorizó Carrera Damas (2012 [1993]) en torno al destino de las sociedades autóctonas de estructura social aparentemente simple. 
La sociedad implantada colonial del valle de Boconó localmente reprodujo el sistema de edificarse sobre la base de las sociedades preexistentes, por ende, la conformación y organización política del actual municipio responde a la organización ancestral, con Boconó como centro y las parroquias de Tostós, Mosquey, Niquitao-Las Mesitas, San Miguel (estas cuatro montadas sobre asentamientos cuicas preexistentes), y San Rafael y Batatal (de origen republicano) como satélites.

Durante la colonia, Boconó fungió como centro de acopio y distribución de productos agrícolas (Rengifo 2006; Morillo y Salas 2009; Cardozo 2013), siendo la caña de azúcar uno de los principales rubros, mientras que el café se fue posicionando a finales del siglo XVIII para alcanzar su apogeo en la sociedad nacional en la segunda mitad del siglo XIX (Moreno, 1994) y principios del XX, en respuesta a la presión comercial del sistema-mundo moderno, formando parte de la región geohistórica del Lago de Maracaibo (Cardozo 2013).

Con este perfil se desarrolló la formación social del actual municipio Boconó que actualmente sufre un crecimiento demográfico con comunidades rurales presionadas a ser urbanas en un período breve de tiempo. Tal es el caso de la parroquia Mosquey, que antes de 1950 solo era un caserío en una extensa zona rural y de su heredad cuica solo se conserva la toponimia. Para la segunda mitad del siglo XX el caserío pasó a ser un poblado favorecido por la construcción de la carretera nacional troncal 007 que ubicó a Mosquey solo a $13 \mathrm{~km}$ del casco central de Boconó (capital del municipio homónimo); ya para principios del siglo XXI pasa a convertirse en centro urbano por la presión demográfica de la mencionada ciudad.

En 1992 Mosquey se transforma en parroquia con más de cinco mil habitantes, pero con pocos elementos para construir su propia identidad local: a partir de 2011 pasó a ser la tercera parroquia más poblada del municipio Boconó, solo después de las parroquias Boconó y El Carmen que conforman el área urbana de la capital del municipio.

Se partió del supuesto de que Las Negreras de Mosquey son una derivación de Los Pastores de San Miguel y se ha innovado en una tradición distinta gracias al intercambio cultural ininterrumpido y resistente a la sociedad colonial $-\mathrm{y}$ luego a la sociedad nacional- que mantuvieron los pobladores de las zonas más septentrionales de Mosquey con otras poblaciones aledañas, así se está conformando una identidad cultural desde los bordes o límites sociales en un creciente proceso de diferenciación y reafirmación con base en un ejercicio de alteridad con localidades y comunidades vecinas, proceso similar a lo sugerido por Barth (1976).

Lo anterior explica por qué la identidad nacional pierde fuerza y ha abierto una posibilidad para construir/reactivar las identidades locales como vías alternas de sujeción a una cultura cocreada in situ. Se asiste a una fase contradictoria donde las personas aún se mueven en un marco nacional que les disminuye, pero, por otro lado, necesitan sujeciones más o menos permanentes arraigadas en memorias colectivas (Díaz Polanco 2013): comienzan a resurgir las identidades locales desde posiciones étnicas o comunales arraigadas a un lugar (Mato, 1990; Canelón 2010), dentro de un orden jerárquico de espacios en el cual se incluye la comunidad o localidad (Gupta y Ferguson 2008). Desde esta perspectiva, Mosquey se está asumiendo como localidad distinta a la capital del municipio Boconó, dentro de la escala regional-nacional, retando a los diseños globales.

Mosquey al construir su identidad local lo hace con un sentido dinámico y procesual en una afirmación y reiteración permanente de la diferencia, nunca es algo estático ni homogéneo, con distintas posiciones y tensiones sobre el nosotros y los otros en un juego abierto a las influencias externas; es un ejercicio de alteridad y reinvención constante, en el cual lo diferente es el complemento de lo ausente en la identidad (Barth, 1976). Esto coincide con lo aportado por Hall (1996) quien propone la metáfora de sutura para referirse a ese doble juego de la persona en cuanto a la aceptación o no de las posiciones sociales asignadas, así como de la interpretación y representación de las mismas desde su subjetividad, en un constante reacomodo y una complementariedad que necesariamente nunca es equivalente ni equitativa: la identidad es un proceso de permanente reconstrucción, de "borradura". El precitado autor señala que esta metáfora también se aplica los sujetos sociales cuyas identidades culturales se construyen dentro de un orden social mayor.

Según Barth (1976: 18) "los grupos posétnicos persisten como unidades significativas solo si van acompañados de notorias diferencias en la conducta, es decir, de diferencias culturales 
persistentes", esto se aplica a la identidad local referida a las relaciones que se originan en un espaciotiempo de lo cotidiano donde lo histórico y lo prospectivo se reúnen para vivir el presente en relación, el nosotros-construyendo, un fin común hacia lo que podemos ser (Hall, 1996); surgen de ese saber fronterizo que puede encapsular o contener ideas liberadoras ante la matriz epistémica de poder moderno (Díaz Polanco 2013; Ortiz 2005).

Mosquey al ser una comunidad con fuerte presión demográfica y empujada a convertirse en urbana en menos de treinta años reviste en su seno una serie de contradicciones de identidad que se agravan por no haber heredado una memoria colectiva elaborada o registrada, su cotidianidad puede verse como un germen de una identidad que se está construyendo desde lo local, por eso, Las Negreras o Las Comparsa de Los Pastores, pueden constituir un rasgo cultural elaborado por la misma comunidad para construir su identidad.

Aquí cabe apuntar lo referido por Hobsbawm (2002 [1983]), para quien las tradiciones son invenciones recientes, sirven para legitimar un nuevo orden social mediante innovaciones o refracciones de los símbolos y valores culturales precedentes, se preocupan por argumentar un origen y pasado común para proyectar un futuro, que usualmente también se inventa. En esto hay coincidencia con lo formulado por Hall (1996). Lo curioso y destacable de este caso, es que quien inventa una tradición no es el Estado ni un actor de este: es una comunidad, no como imposición o justificación de un orden nuevo, sino como una forma de resistencia cultural y autoafirmación para no verse diluida en una eventual conurbación con la ciudad de Boconó según el diseño global.

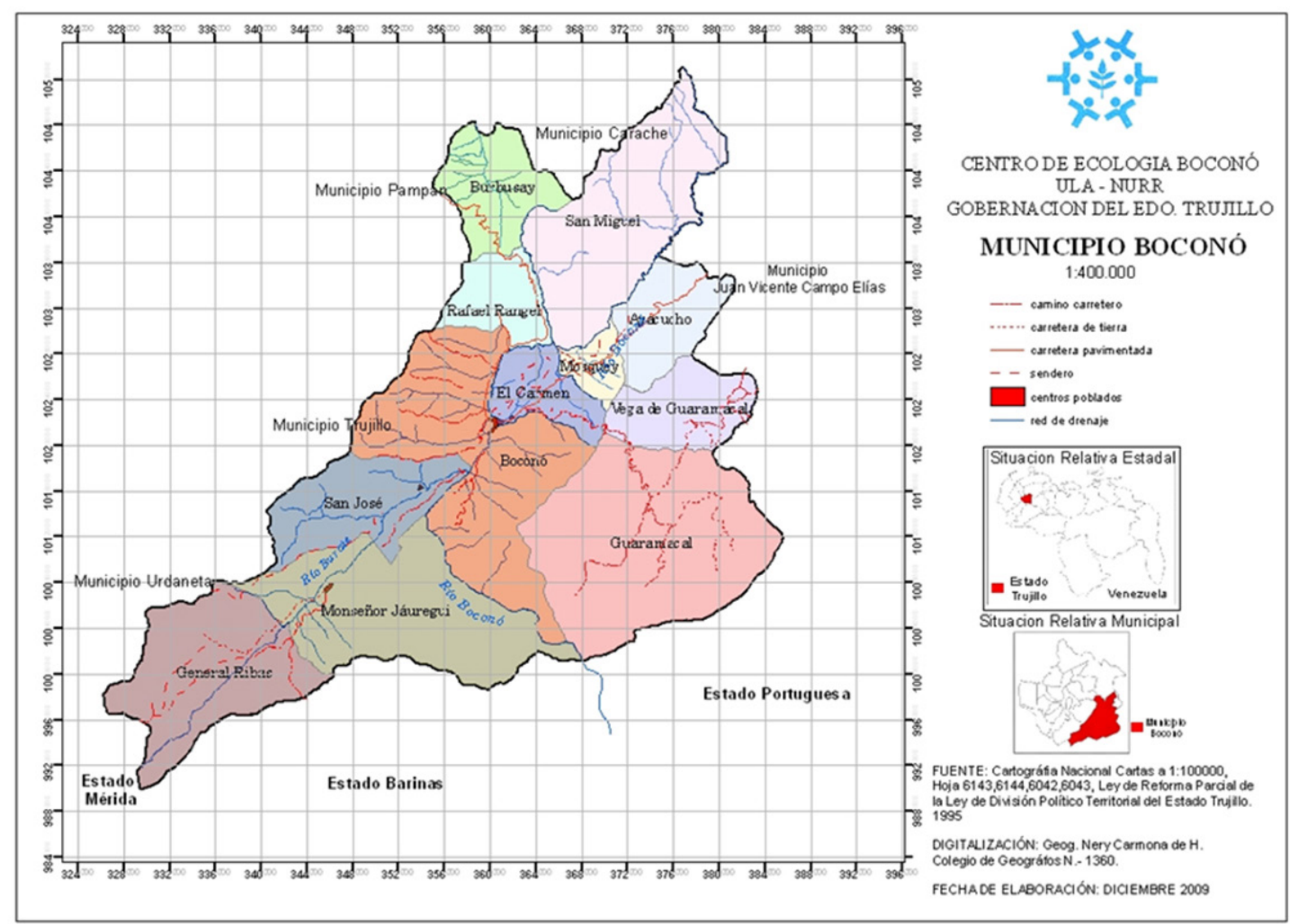

Figura 1. Mapa del municipio Boconó del estado Trujillo, Venezuela.

Fuente: Centro de Ecología de Boconó (2009). 


\section{Recorrido investigativo}

El propósito de la investigación fue analizar Las Negreras de Mosquey como manifestación artística religiosa sincrética de acuerdo a las categorías del pensamiento fronterizo. Se hicieron inmersiones en Las Negreras de Mosquey durante los años 2015-2017, realizando entrevistas a promotores, espectadores, así como observaciones con apoyo de grabadora de video, audio y cámara fotográfica. Tales acciones se realizaron previos y durante los recorridos de las negreras de: La Hoyada I del 10 de enero de 2015; de La Cuchilla del 8 de febrero de 2016; La Boca del Monte del 14 de enero de 2017, La Hoyada III del 21 de enero de 2017.

Se hicieron entrevistas a profundidad, así como informales y grupales, estas últimas se dieron de forma espontánea a petición de los participantes. Se hizo una devolución sistemática de lo recogido por la investigación en el patio común de la macro-familia (familia extensa más otros grupos familiares que se adhieren a su liderazgo)
Zambrano en La Hoyada III. Se tomaron notas del equipo de investigación de las observaciones y recepción de la comunidad. Las entrevistas y los registros de observación fueron transcritos y se les aplicó análisis de contenido.

\section{Breve descripción de Las Negreras o La Comparsa de Los Pastores de Mosquey}

Los elementos sincréticos de otras tradiciones de forma innovadora se ensamblan en "Las Negreras de Mosquey" como expresión alterna para erigir una identidad local a partir de un ejercicio de alteridad con manifestaciones artísticas similares de otros lugares de la región: resulta ser una tradición inventada (Hobsbawm 2002 [1983]). La tradición, sin registro escrito, consiste en el paseo del Niño Jesús (imagen-escultura) por todos los sectores de Mosquey muy similar a la Romería de Los Pastores. En algún punto del paseo, el Niño es robado (afinidad con el Velorio del Niño Jesús, el Niño Jesús Perdido, Serenada del Niño, Paradura).

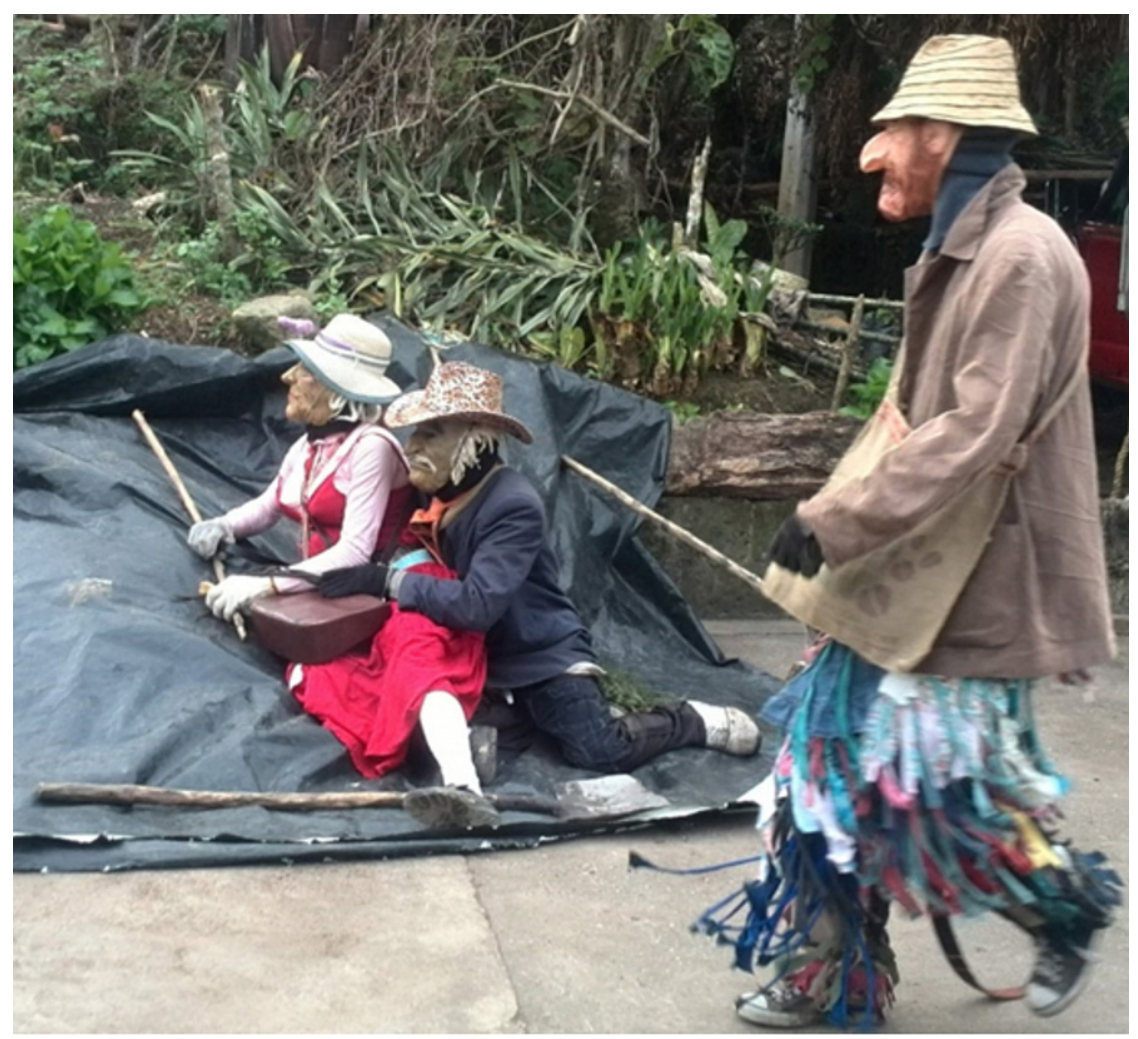

Figura 2. La Vieja, El Viejo y El Bobo, principales pastores-disfrazados durante La Negrera de la Boca del Monte, 14/01/2017. 
Las negreras son una especie de comparsas que conforman la tradición de La Romería de Los Pastores de San Miguel, pero mientras en esta festividad son un tipo de comparsas accesorias, aparecen a finales del siglo XX en Mosquey como eje central de una nueva manifestación, situación que se refuerza en la primera década del siglo XXI. Según los promotores y participantes esta tradición es originaria de Potrero Grande, Las Hoyadas y la Boca del Monte, a finales del siglo XX fue que "subieron" hasta el actual casco central, el cual surgió gracias a la construcción de la troncal 007, pues el Camino Real estaba mucho más al norte y atravesaba lo que hoy se denomina Boca del Monte, donde, hasta la primera mitad del siglo XX, se hallaba el eje central de lo que hoy se ha denominado Mosquey.

Los personajes centrales son similares a los de La Romería de Los Pastores de San Miguel ellos son: El Viejo, La Vieja y El Bobo (hijo de los primeros) quienes se encargan de la custodia del Niño-Dios durante el paseo. Su intención es visitar todos los hogares de quienes demuestran su disposición a recibirlos con los portones y la puerta principal abierta. Los pastores-cantistas son quienes cantan coplas y versos al Niño-Dios, anuncian y narran la secuencia desarrollada en la manifestación artística, el capitán es el líder de los pastores-cantistas y el tesorero o la tesorera es el/ la líder de la comparsa en general y decide dónde se dirige la imagen del Niño-Jesús. Los pastores-cantistas están conformados por al menos cinco parejas de coros quienes portan y ejecutan los instrumentos musicales (cuatro, tambor, maracas), se les suma el cachero quien con una guarura anuncia a la comunidad receptora la llegada de la comparsa.

El Diablo y su séquito boicotean el paseo liderado por el/la tesorero/a y los pastores-cantistas con obstáculos improvisados, al tiempo que se alegran y vitorean una vez que el Niño-Jesús se pierde, mientras La Vieja, El Viejo y El Bobo (líderes de los pastores-disfrazados) lloran y se lamentan amargamente. Los pastores-disfrazados o pastores-sueltos son quienes con máscaras y representación de personajes cotidianos acompañan el recorrido. Otros personajes complementarios y sustituibles son El Mono, que tiene un séquito (manada de monos), cuyos trajes se hacen con barba de palo y su máscara en la actualidad se

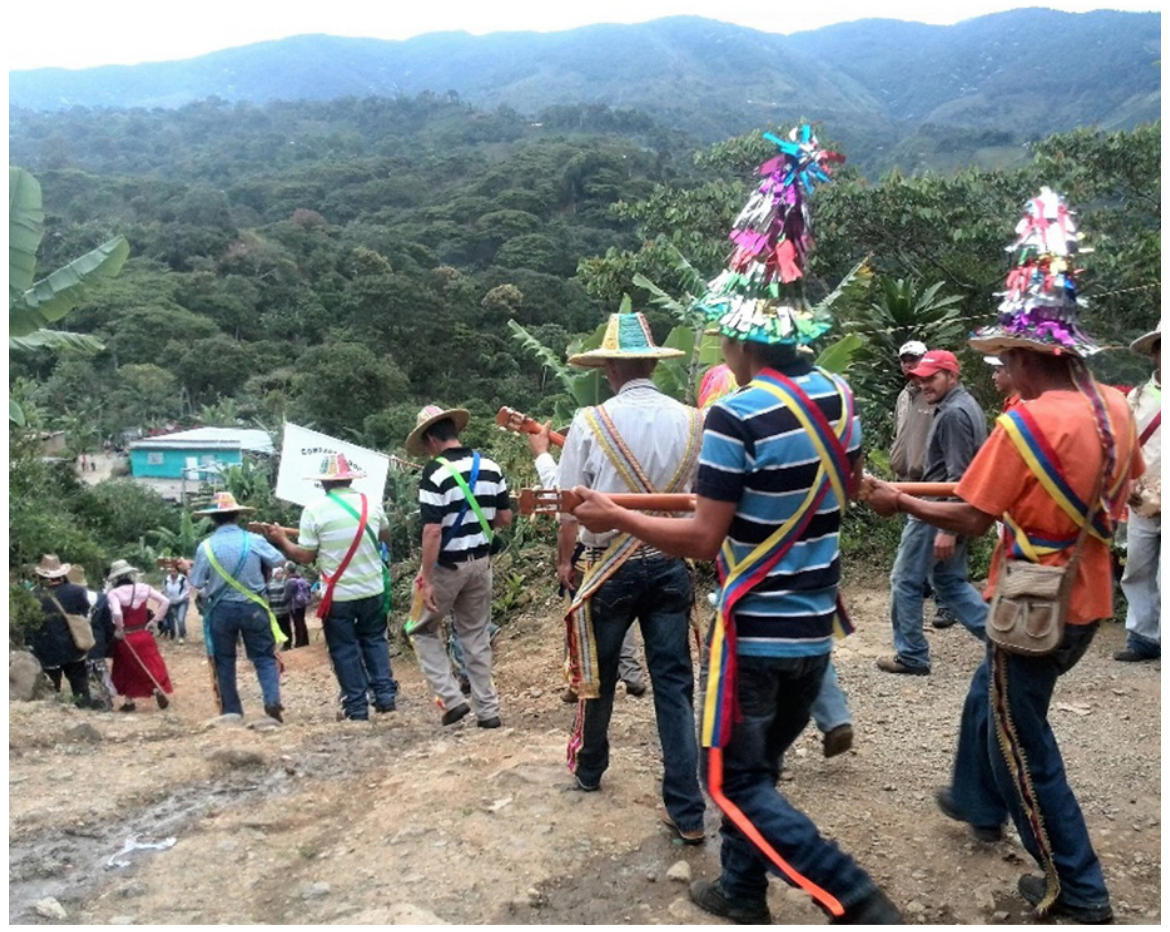

Figura 3. Parejas de pastores-cantistas durante La Negrera de la Boca del Monte, 14/01/2017. 
sustituyó por una de gorila hecha de látex, están los hombres disfrazados de mujer denominados Las Carolinas quienes ponen el toque jocoso a la actividad que se prolonga desde las siete de la mañana hasta cerca de la medianoche. La gran comparsa de pastores-disfrazados puede ser considerada como "las negreras" propiamente dichas, hacen puestas en escena improvisadas con los elementos agrícolas o urbanos que emergen en el recorrido, bromean con el público y ayudan a Los Viejos y al Bobo a contener el sabotaje de El Diablo y La Muerte junto a sus secuaces con disfraces similares (brujitas, fantasmitas, diablillos).

Durante el recorrido se hacen presentaciones escénicas simultáneas. Por una parte, cuando el Niño-Jesús visita cada casa donde es esperado con un pequeño altar y una vela blanca, los pastores-cantistas, entonan versos y coplas al Niño-Dios, les agradecen a los visitantes su hospitalidad y su devoción (siempre de forma cantada) y también narran la historia: si el Niño está alegre, si se extravió, si se está buscando y, finalmente, si apareció. Por otra parte, afuera de la casa visitada están El Diablo y/o La Muerte y sus séquitos intentando sabotear a toda costa el paso a los pastores-cantistas y el Niño-Dios, mientras que los pastores-disfrazados y Los Monos les juegan chanzas y bromas a los espectadores.

De los pastores-disfrazados solo La Vieja, El Viejo y El Bobo pueden entrar a las casas con la imagen y los pastores-cantistas, de ahí se infiere su carácter sacerdotal, ya que forman parte de quienes sacralizan el espacio. Por su parte, los espectadores son personas que reciben a los visitantes en las casas o en las calles o ven pasar las comparsas desde azoteas y balcones, o bien acompañan a toda la comparsa en todo o en parte del recorrido, no poseen velas a diferencia de otras tradiciones de origen navideño y religioso. Los espectadores que acompañan el recorrido se mezclan con los pastores-disfrazados.

Durante el recorrido se pueden hacer, o no, presentaciones de otras tradiciones artísticas y religiosas como El Baño de San Benito, El Baile de La Cinta, Rezo Cantado del Niño Jesús (este generalmente representa el cierre y es una actividad invariable). Los pastores-disfrazados hacen coreografías, dramatizaciones y peleas de correazos (latigazos) entre ellos, algunas son ensayadas, pero la mayoría son improvisadas cuando surge un espacio abierto en el recorrido. El principal objeto de las bromas son El Bobo y uno que otro espectador desprevenido. Las escenografías se arman en función de los personajes disfrazados los cuales varían cada año, y de negrera y negrera. Se representan figuras cotidianas: enfermeras, prostitutas, mujeres coquetas o fatales, así como personajes de la vida pública que estén de moda como, por ejemplo, políticos.

Las Negreras de Mosquey se celebran los sábados, comienzan desde el primer sábado de enero y pueden prolongarse hasta el sábado anterior a Semana Santa, en este aspecto rompen con la tradición de celebrar al Niño-Jesús hasta el 2 de febrero, Día de la Virgen de la Candelaria. Cada comparsa de Las Negreras de Mosquey puede ser organizada por una familia, un grupo de familias, una calle o bien un sector que en realidad viene a ser la organización y liderazgo de una familia extensa a la cual se le adhieren algunas familias vecinas, a este tipo de organización comunal se les categorizó, en esta investigación, como macro-familia. La plasticidad de sus rituales y de los personajes permiten diferenciar una negrera de otra. Según los habitantes de Mosquey y los promotores de esta tradición algunas son "más organizadas", otras "más devocionales o religiosas" y otras con más elementos paganos. Aquí se observa cómo al interior de la comunidad la identidad que se va conformando no es homogénea sino heterogénea y dinámica con relaciones tensas que solo tienen en común buscar la diferencia-complementariedad con un otro considerado externo (Barth, 1976).

\section{Diálogo entre tradicionalidad y modernidad en Las Negreras de Mosquey}

Cabe mencionar que la tradición de "Las Negreras de Mosquey" hace aproximadamente 25 o 50 años no eran similares a las actuales. Décadas atrás, cuando Mosquey era una zona más rural que urbana, las negreras consistían simplemente en comparsas de pastores disfrazados que visitaban las casas y propinaban correazos a cualquier desprevenido aprovechando la máscara (otrora confeccionada con cuero de chivo o cualquier otro animal vacuno) para ocultar su identidad.

El aspecto devocional, esta vez, propio e innovador de "Las Negreras de Mosquey" es el hecho que quienes desean un favor, basado en un acto de fe, se encargan de "vestir al Niño", es 
decir, diseñar y confeccionar el ajuar en su salida de una negrera, o prestarse para ser "el ladrón", ya que cuando el Niño aparece, su usurpador es castigado por La Vieja, El Viejo y El Bobo derramando cera derretida de velas en los brazos. Esta dramatización está presente en algunas negreras, pero en otras quien recibe el castigo es el/la tesorero/a (líder de la comparsa). En este punto cabe destacar que no se habla de cofradías.

Las innovaciones y distanciamiento de "Las Negreras de Mosquey" con respecto a sus predecesoras de hace décadas se debe a una nueva generación, que en la primera década del siglo XXI, ha introducido elementos gerenciales vinculados con la planificación, la logística y la gestión de recursos. Llama la atención la distinción entre las generaciones actuales que fungen como organizadores y promotores de la tradición inventada, quienes se autodefinen como "devotos" y no como "pagadores de promesa", pues estas últimas significan que quien organice una negrera debe cumplirla anualmente, de lo contrario, sería objeto de malos augurios para su familia, entre las que destaca la afectación de la salud y de la prosperidad (malas cosechas).
Estos argumentos indican una frontera epistémica, pues hay un halo sobrenatural que favorece que una negrera "salga", pero dicho halo se ve favorecido si se "planifica y gestiona con tiempo", ya que si esta racionalidad se hace desde la fe y la fijación de las metas, "el Niño-Dios" ayuda. Aquí son evidentes los indicios de un saber fronterizo integrador de la racionalidad lógica e instrumental con la emocionalidad, para dar con la razón emocional, destino planteado por Lanz (2012), máxime, es un diálogo entre la tradicionalidad y la modernidad (García Canclini, 1990), es un saber fronterizo.

Esta racionalidad emocional permitió que la tradición no desapareciera: en primer lugar, por su empeño de continuarla a pesar de la resistencia de la generación precedente y, en segundo lugar, porque han establecido normas para limitar los excesos como la desproporcional ingesta de alcohol durante el recorrido y la violencia de los pastores-disfrazados por medio de los correazos, así como el hecho de pedir dinero a los espectadores y el gastarle bromas pasadas de tono. De esta generación de innovadores surgió la idea de que las negreras cubran todos los caseríos, sectores,

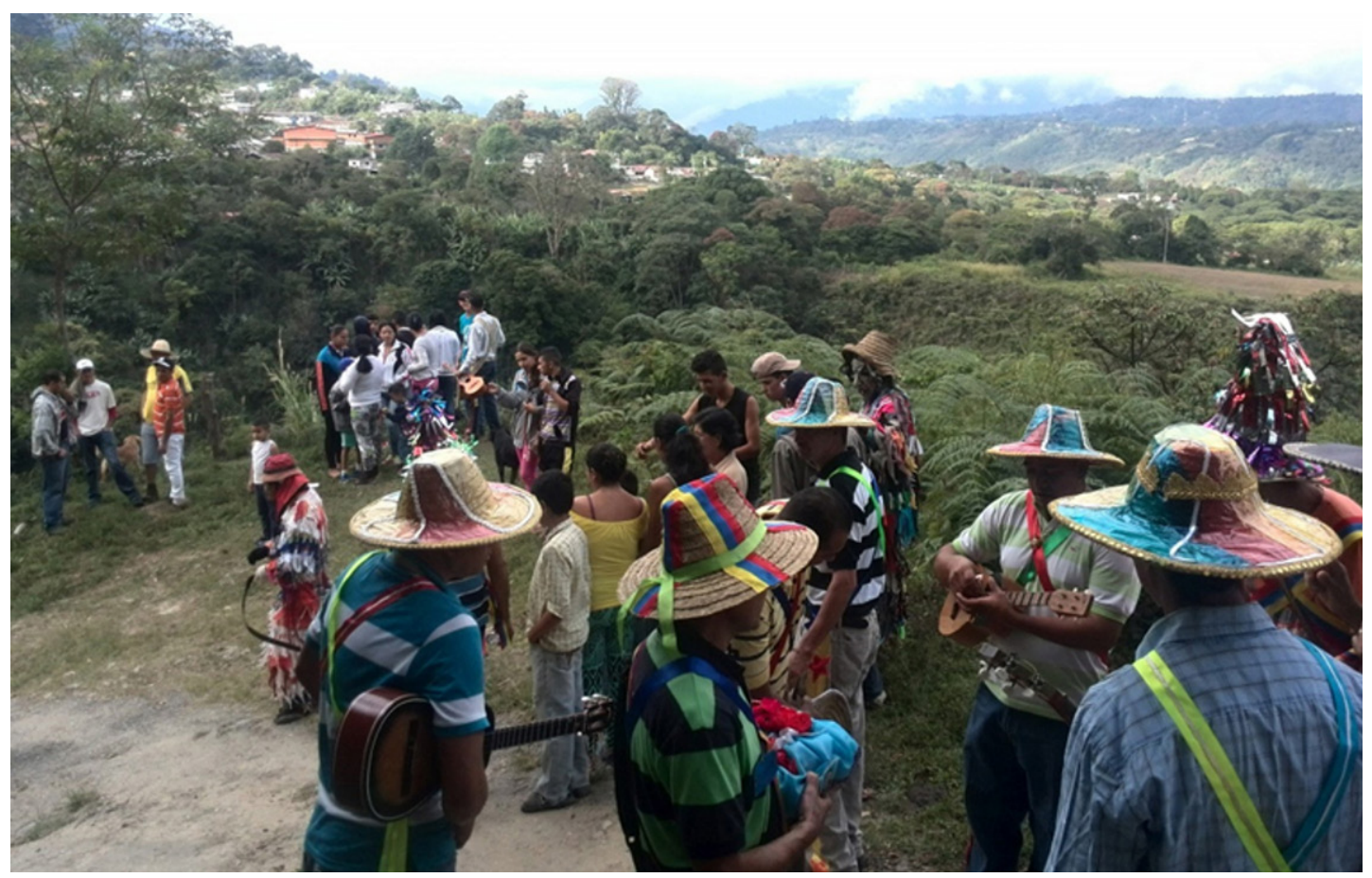

Figura 4. El paisaje urbano y rural de Mosquey se integra mediante el recorrido de La Negrera de la Boca del Monte 14/01/2017. 


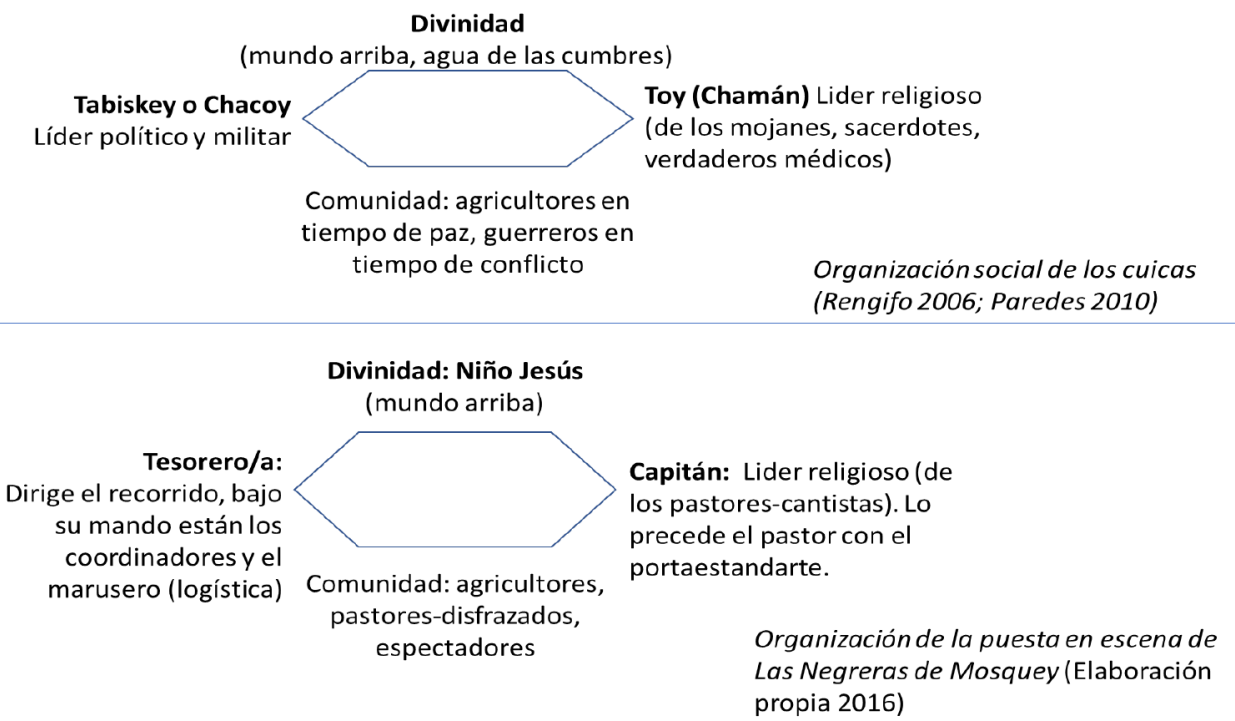

Figura 5. Similitud entre la organización social cuica y la organización de la puesta en escena de Las Negreras de Mosquey.

calles, caminerías y trochas de Mosquey lo que evidencia el intento de sujetarse a la tradición como elemento de identidad local no tanto como de "dónde venimos" sino en torno a un "quiénes queremos ser" (Hall, 1996); de aquí su vinculación con el espacio, y su empeño de construir un lugar más allá de identificarse solamente con un territorio.

En consecuencia, se han creado personajes y se les ha adjudicado roles: por ejemplo el $m a$ rusero quien se encarga de recoger el dinero, las botellas de licor (generalmente miche), y otros obsequios donados en las casas visitadas en una marusa; para luego administrarlos adecuadamente. En las negreras "menos religiosas" que han aceptado los personajes de El Diablo o La Muerte, a estos se les ha adjudicado la función de parar y guiar el tráfico de automóviles cuando atraviesan la carretera nacional. La logística para hacer los descansos, la hidratación y los refrigerios en combinación con los aportes y colaboración de la comunidad (el recorrido dura más de doce horas) es una muestra del uso de procesos gerenciales en la manifestación.

Por otra parte, la puesta en escena de Las Negreras de Mosquey ha innovado epistemes ancestrales. De la vertiente ibérico-islámica (moros): hay innovación de la representación de los hombres disfrazados de mujer, el baile de la cinta, baile y traslado en parejas, bailes que se cruzan, rostros ennegrecidos; de la ancestralidad andina cuica coincide la organización de la manifestación con la organización social ancestral el Tesorero/a puede representar a Tabisquey o Chacoy -líder político y militar-, mientras que el Capitán líder de los pastores-cantistas (cantadores de los versos) sería el equivalente al Toy (Chamán), esta inferencia se apoya en el argumento planteado por Clarac de Briceño (2016 [1976]) quien estipula que los cantistas de las festividades campesinas andinas expresan la verdadera autoridad sacerdotal de la comunidad.

Por su parte La Vieja, El Viejo y El Bobo pueden ser la representación de una clase sacerdotal ancestral cuica más próxima al pueblo o la comunidad; esta inferencia se hizo porque solo ellos, de los pastores-disfrazados, pueden entrar a los hogares y forman parte del ritual, junto a los pastores-cantistas, consistente en vueltas en círculos frente al pesebre mientras la imagen del Niño-Dios visitante acompaña al Niño-Dios visitado.

Por eso estos tres personajes, líderes y defensores de los pastores-disfrazados, pueden ser la representación de esa diferenciación de castas sacerdotales que en el momento de la conquista estaba emergiendo en las comunidades prehispánicas de los andes venezolanos que se 


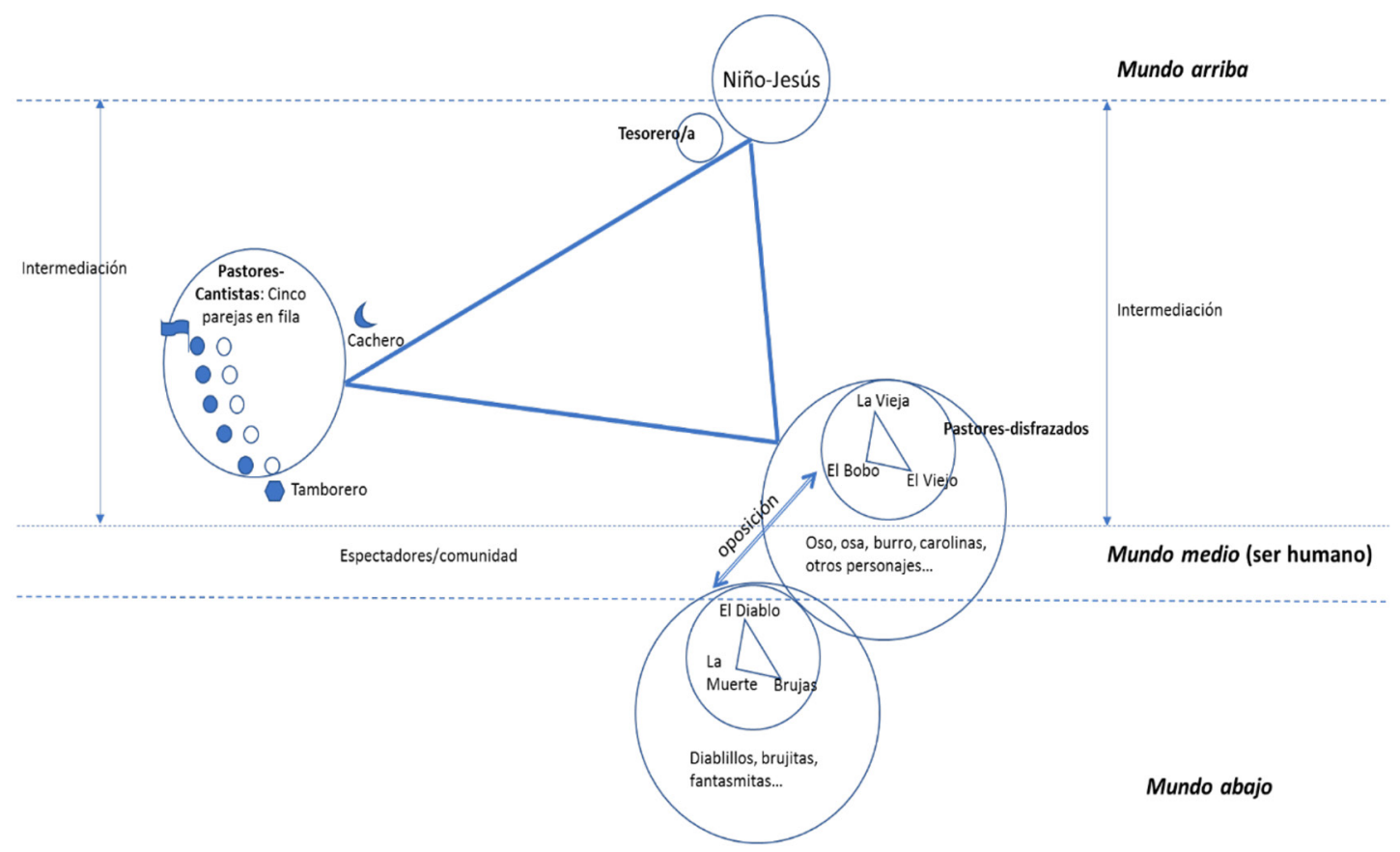

Figura 6. Ontología subyacente en Las Negreras de Mosquey.

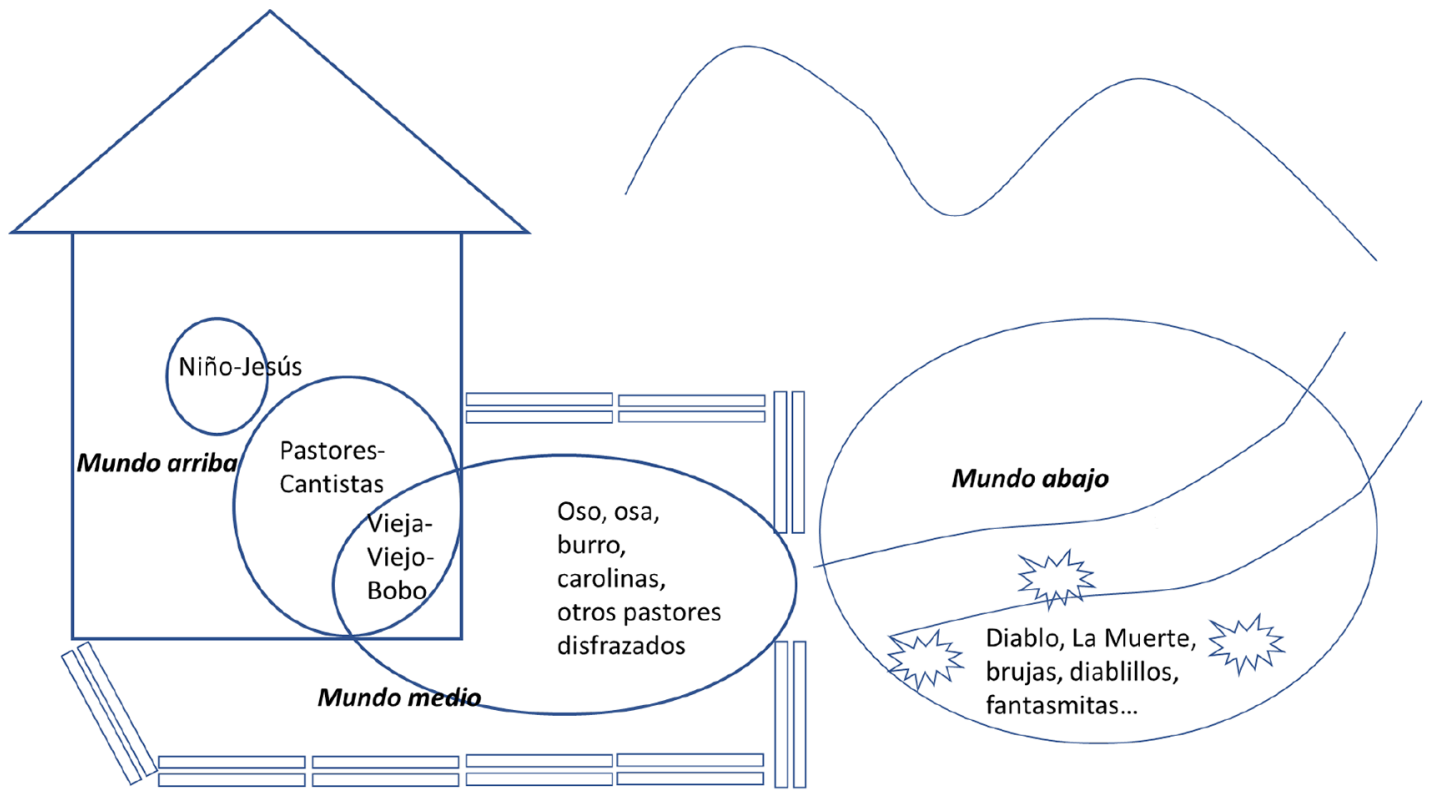

Figura 7. Sacralización del espaciotiempo de los hogares según el pensamiento metafórico de Las Negreras de Mosquey.

diferenciaba de una casta sacerdotal más próxima a los templos o centros de peregrinación, en este caso, representado por los pastores-cantistas (Cf. Burguera, 1982; Warner, 1987; Clarac de Briceño 2016 [1976]).

\section{A manera de conclusión}

Las Negreras de Mosquey contienen y son espacios vivos del pensamiento o saber fronterizo contentivo de: 
Se halló un pensamiento otro consistente en: un pensamiento holístico expresión de una racionalidad que es apenas un aspecto de toda una forma de simbolizar y representar; también hay procesos abstractivos a partir del sentir a través de la devoción y una conexión constante con la naturaleza (racionalidad emocional); un pensamiento sustentado en la ancestralidad cuica mediante la organización de la manifestación por macro-familias; una espaciotemporalidad otra donde se expresa la concepción del espaciotiempo campesino como continuidad que no entra en contradicción con la concepción moderna del espacio y tiempo.

La representación constante de la triada dinámica como ontología, propia de la ancestralidad cuica y la matriz cultural campesina andina; representación ancestral del mundo arriba/mundo medio/mundo abajo; pensamiento táctico y estratégico a partir de lo emergente para realizar el recorrido. Una construcción y sujeción de una identidad local como resistencia y reto a la imposición de Boconó como centro urbano y su subsecuente implantación del diseño global actual.

Es una tradición inventada que construye una identidad local en intercambio abierto con otras comunidades que sirve de afirmación de una diferenciación y complementariedad (Barth, 1976, Hall, 1996). Por ende, está creando e imaginando un origen y un pasado común, al analizar en profundidad las entrevistas, los promotores coincidían en que el responsable de su activación fue una celebridad de la comunidad que se denominaba Tatuque, un adulto mayor que solo vivía para animar la salida y organización de las negreras. Este personaje parece ser una especie de padre-fundador de Las Negreras de Mosquey quien impulsó a las generaciones de promotores en las postrimerías del siglo XX para organizar las negreras y darles un carácter más organizado (Bastidas 2016).

Gnosis fronteriza: Los promotores de Las Negreras de Mosquey hacen una invitación a dialogar con las instituciones modernas (interculturalidad extendida, Puentes 2015; Vittar 2011) y los investigadores críticos, mediante una cierta consciencia de su religiosidad alterna y un reconocimiento de sus epistemes innovadas en su tradición inventada. Para los promotores de Las Negreras de Mosquey, la manifestación sirve como protector contra el uso no programado del tiempo libre, la delincuencia juvenil y el abuso de drogas; también fue evidente su conexión con su ancestralidad que permitió valorarse como comunidad, hecho palpable registrado durante la devolución sistemática de la investigación a la comunidad.

Otros indicios de gnosis fronteriza y potencialidad de interculturalidad extendida: apertura con los líderes de la iglesia católica para enriquecer la tradición; reto para romper las separaciones modernas de la investigación entre: investigador/ investigador, entrevistador/entrevistado, observador/contexto; forma alterna de narrar una historia metaforizada de la comunidad a través de la festividad, es decir, se está creando un origen y pasado común de la manifestación que coincide con el origen de Mosquey como localidad y no como sector rural; vinculación con los líderes de la manifestación como líderes de la comunidad; posibilidad de construir una historia local otra (metaforizada) en colaboración con los investigadores críticos y la posibilidad de convertir el poder agenciante de la manifestación en poder instituido como forma de resistencia y liberación; creación de las negreras de niños para preparar la generación de relevo; combinación de los conocimientos modernos y tradicionales para la confección de máscaras e implementos.

Lengua otra: Sentidos y significados presentes en los rituales y ceremonias que están contextualizados y se distinguen de los modernos; expresión y comunicación por medio de la música tradicional; ritual del miche para socializar y crear lazos de hermandad; palabras tradicionales del español que se han conservado y ya están casi en desuso en la sociedad moderna; comunicación a través de los rituales y las coplas.

Adicionalmente una socioestética otra: "se entiende desde la pluridiversidad de las corporeidades que se oponen a la razón y estética universalizante del sistema mundo moderno" (Pérez y otros, 2011: 32): puestas en escenas a cielo abierto; disfraces, que trastocan y retan los patrones legitimadores del arte moderno y en la cual cobra sentido la ecopolítica, el don recíproco, el sentido comunitario; embellecimiento del espacio público e improvisación de puestas en escenas teatrales dramáticas o jocosas de forma colectiva y espontánea con participación e integración de algunos espectadores; actitud retadora de los 
cánones del arte moderno basados en la dicotomía productor-artista/espectador.

Las Negreras de Mosquey, efectivamente, demuestran que las manifestaciones artísticas sincréticas religiosas pueden ser abordadas y vistas como pensamiento o saber fronterizo que contiene epistemes y subjetividades distintas a la lógica moderna, que no solo la trastocan, sino que han estado en diálogo con ella desde su implantación como matriz epistémica de poder.

Los estudios decoloniales, según esta investigación, pueden dar importantes aportes para abordar las manifestaciones artísticas religiosas sincréticas yendo más allá de una simple descripción de sus productos, en cierta forma es una respuesta a los planteamientos realizados por García Canclini (1990): sirven como punto de inicio para la fundamentación y consistencia epistémica para las expresiones culturales que dialogan con la modernidad desde dentro o fuera de ella, y simultáneamente, da cuenta de los procesos, las vivencias, las subjetividades y las epistemes en ellas contenidas.

Mosquey, en los diseños globales dentro del sistema mundo moderno ocupó un lugar periférico y prácticamente invisible, su rol asignado fue el de productor agrícola para proveer el centro de acopio ubicado en Boconó, como parte de la región geohistórica del Lago de Maracaibo. Con la entrada en vigencia y el agotamiento del modelo rentista petrolero de Venezuela, Mosquey se advierte como una comunidad urbana pero no está dispuesta a verse diluida en la conurbación que tiene como centro la ciudad de Boconó: de forma inconsciente inventó una tradición que sirve para construir su identidad local, pero aún está pendiente cómo sobrevive como localidad, si mantiene, innova o reinventa su vocación agrícola como modo de subsistencia y si conserva, reacomoda o trasciende, su relación dependiente con la ciudad de Boconó. En otras palabras, si pasa de la persistencia-resistencia a la agencia e institucionalidad teniendo en contra el lugar invisible que hasta ahora le han adjudicado desde los diseños globales.

Tal resistencia a ser integrada a la conurbación con centro a la ciudad de Boconó puede explicarse por la organización ancestral cuica de aldeas o centros poblados autónomos e interrelacionados. Otra posible explicación de esta resistencia cultural son los efectos de la diferencia colonial: Mosquey al ser subalternizada, invisibilizada y excluida, por tanto tiempo, ahora reclama su lugar e intenta construirlo a partir de una tradición inventada, que prácticamente es lo único que posee según sus promotores. En consecuencia, representa un recurso para la construcción de una identidad local, donde se evidencia la potencia heurística de los planteamientos teóricos en torno a la identidad de Hobsbawm (2002 [1983]), Hall (1996), García Canclini (1990) y Barth (1976), quienes la definen como procesual, dinámica, innovadora, resultante de un doble juego entre una diferenciación/complementación con otros que sirve de autoafirmación de un nosotros, de un decirnos, una autorreferencia y un imaginarnos hacia un futuro común.

\section{Referencias Citadas}

Albarrán, M.; Linares, J.; Marín, M. y Pérez, Ana

2014 "Perspectiva histórica de Trujillo durante la época precolombina". En Perspectivas. Revista de Historia, geografía, arte y cultura. Vol. 2, 3: 107-118.

Barth, F.

1976 Los grupos étnicos y sus fronteras. La organización social de las diferencias culturales. Fondo Cultura Económica, México.

Bastidas, F.

2016 "Las Negreras de Mosquey: un caso de construcción y sujeción de identidad local". En Revista Estudios Culturales. Vol. 9, 18: 69-83.

Burguera, M.

1982 Historia del Estado Mérida. Ediciones de la Presidencia de la República, Caracas, Venezuela.
Canelón, F.

2010 Política de la alteridad. Consejo de Desarrollo Científico y Humanístico de la Universidad Central de Venezuela, Caracas, Venezuela.

Cardozo, Germán

2013 "El circuito agroexportador de la región histórica del lago de Maracaibo: siglos XVI al XIX". Revista $C \& P$, 4: $125-155$

Carrera Damas, G.

2012 [1993] De la dificultad de ser criollo. CEC-El Nacional, Caracas, Venezuela.

Clarac de Briceño, J.

2016 [1976] La cultura campesina en los andes venezolanos. Editorial El Perro y la Rana: Caracas. 
De Sousa, S. B.

2010 Refundación del Estado en América Latina. Perspectivas desde una epistemología del sur. Lima: Instituto Internacional de Derecho y Sociedad.

Díaz-Polanco, $\mathrm{H}$.

2013 Elogio a la diversidad. Globalización, multiculturalismo y etnofagia. Segunda edición. Monte Ávila Editores Latinoamericana, Caracas, Venezuela.

Dubuc de Isea, L.

2013 La nación cuyca. Manuscrito en posesión de la autora. Oficina Cronista Oficial, Concejo Municipal del Municipio Boconó, Venezuela.

Dussel, E.

2000 "Europa, modernidad y eurocentrismo". En La colonialidad del saber: eurocentrismo y ciencias sociales. Perspectivas latinoamericanas, editado por Edgardo Lander, pp. 41-54. Consejo Latinoamericano de Ciencias Sociales, Buenos Aires, Argentina.

Fanon, F.

1961 Los condenados de la tierra. Fondo de Cultura Económica, México.

García Canclini, N.

1990 Culturas híbridas. Estrategias para entrar y salir de la modernidad. Ediciones Grijalbo, México.

García, J.

2006 Caribeñidad. Afroespiritualidad y afroespitemología. Editorial El Perro y La Rana, Caracas.

Gupta, A. y Ferguson, J.

2008 "Más allá de la cultura. Espacio, identidad y políticas de la diferencia". En Antípoda, 7, 235-256.

Hall, S.

1996 ¿Quién necesita "identidad”? Cuestiones de Identidad Cultural. Compilado por Stuart Hall y Paul du Gay, pp. 13-39. Amorrortu Editores, Madrid.

Hobsbawm, E.

2002 [1983] "La invención de la tradición". Invención de la tradición. Editado por Eric Hobsbawm y Terence Ranger, pp. 7-21. Editorial Crítica, Barcelona-España.

Lanz, R.

2012 Diez preguntas sobre transcomplejidad posmoderna. Manuscrito enviado por correo electrónico el 5 de marzo.

Lepe, L.

2008 "Pensamiento fronterizo y tradición oral. La perspectiva desde el postoccidentalismo de Walter Mignolo". Diálogos Culturales. Compilado por Niria Suárez, pp. 79-104. Archivo Diocesano de Mérida-Grupo de Investigación y Estudios Culturales de América Latina, Mérida-Venezuela.

Mato, D.

1995 Crítica a la modernidad, globalización y construcción de identidades. Consejo de Desarrollo Científico y Humanístico de la Universidad Central de Venezuela, Caracas, Venezuela.

Moreno, A.

1994 "Desarrollo histórico de la organización del espacio en la región andina (estados Trujillo, Mérida, Táchira)".
En La región histórica. Segunda Edición. Tropikos, Caracas, Venezuela.

Morillo, G. y Salas, G.

2009 "La cuenca del Lago de Maracaibo como unidad geohistórica”. Agenda Social. Vol. 3, 1: 78-99.

Ortiz, R.

2005 Mundialización: saberes y creencias. Gedisa, Barcelona, España.

Pérez, C.; Meléndez, L.; Vázquez, B. y E. Iazzetta

2011 "De la estética binaria a las socioestéticas plurales". En Revistas Estudios Culturales, Vol. 4, 7: 15-50.

Puentes, J.

2015 "Descolonización metodológica e interculturalidad. Reflexiones desde la investigación etnográfica". Revista Latinoamericana de Metodología de las Ciencias Sociales, Vol. 5, 2: 1-19.

Quijano, A.

2007 Colonialidad del poder y clasificación social. El giro decolonial. Reflexiones para una diversidad epistémica más allá del capitalismo global. Editado por Santiago Castro-Gómez y Ramón Grosfoguel, pp. 93-126. Bogotá: Siglo del Hombre Editores/Universidad Central/ Instituto de Estudios Sociales Contempráneos-Pontificia Universidad Javeriana/Instituto Pensar.

Rengifo, D.

2006 Breve historia ilustrada de Trujillo. Fondo Editorial Arturo Cardozo, Trujillo, Venezuela.

Suárez de Paredes, N. y Castillo, B.

2000 "Trabajo y cultura campesina: un análisis testimonial de comunidades de los valles altiandinos". En Boletín del Archivo Arquidiocesano de Mérida. Vol. VIII, 20: 123-146.

Vittar, C.

2011 El estudio de la confianza intercultural en el marco de la globalización: de la incapacidad teórica-metodológica a un modelo explicativo alterno. Formas otras: saber, nombrar, narrar, hacer. IV. Trainnign seminar de jóvenes investigadores en dinámicas interculturales, pp. 191-201. Centros de Estudios y Documentación Internacionales de Barcelona, Barcelona-España

Wagner, E.

1987 Arqueología de Los Andes venezolanos. En Revista de la Dirección General de Cultura de la Universidad de Los Andes, 14: 5-15.

Wallerstein, I.

2006 Análisis de Sistema - Mundo. Una introducción. Siglo XXI, México-Buenos Aires-Madrid.

Walsh, C.

2007 Interculturalidad y colonialidad del poder. Un pensamiento y posicionamiento del otro desde la diferencia colonial. El giro decolonial. Reflexiones para una diversidad epistémica más allá del capitalismo global. Editado por Santiago Castro-Gómez y Ramón Grosfoguel, pp. 47-62. Bogotá: Siglo del Hombre Editores/Universidad Central/Instituto de Estudios Sociales Contempráneos-Pontificia Universidad Javeriana/Instituto Pensar. 


\section{Notas}

1 La diferencia colonial según Quijano (2007: 96) puede definirse como: "una concepción de humanidad, según la cual la población del mundo se diferencia en inferiores y superiores, irracionales y racionales, primitivos y civilizados, tradicionales y modernos".

2 Para García (2006) es más apropiado usar en término hispanoárabe ya que el Estado Español es un proceso que se inició en la conquista en alteridad con sus colonias de ultramar, por ende, es erróneo hablar de conquistador o colono español.

3 Se asume la resistencia cultural como las subjetividades y epistemes alternas a la modernidad que han pervivido y sobrevivido a la diferencia colonial mediante una constante innovación; a esas tensiones de procesos de invisibilización-visibilización, obliteración-expresión cultural al interior de las comunidades en el marco de la geopolítica y corpo-política impuesta por la matriz epistémica de poder moderna/colonial.

4 Término acuñado por Fanon (1961) para hacer referencia el ser subalternizado mediante la implantación del proyecto moderno a través de la colonialidad (por medio de la diferencia colonial). Es el ser subyugado que resiente la herida colonial -infringida por la diferencia colonial-.
5 Esta investigación develó que el ancestro ibérico-islámico se ha invisibilizado en la historia oficial, pero dejó su huella encubierta en las festividades tradicionales andinas venezolanas. Se prefiere usar este término y no moro o morisco por las connotaciones peyorativas y subalternizadoras que contiene.

6 Los estudios decoloniales a través de Wallerstein (2006) han asimilado el concepto de sistema mundo moderno para hacer alusión a la expansión e imposición del proyecto moderno en el ámbito global que ha creado una geocultura y ha establecido una red de poder sustentada en la justificación de la colonialidad a través de la modernidad. Se asume que modernidad y colonialidad son procesos biunívocos

7 Hasta ahora sigue en discusión si existió una(s) etnia(s) o nación cuica. Las "parcialidades cuicas", que se conocen hoy, son elaboraciones de los cronistas y conquistadores sobre la base de ubicaciones geográficas y cacicazgos por ellos identificados. Ciertamente todo apunta a que hubo una unidad lingüística $-\mathrm{y}$ por ende cultural- de estos grupos con algunas varianzas dialectales. 